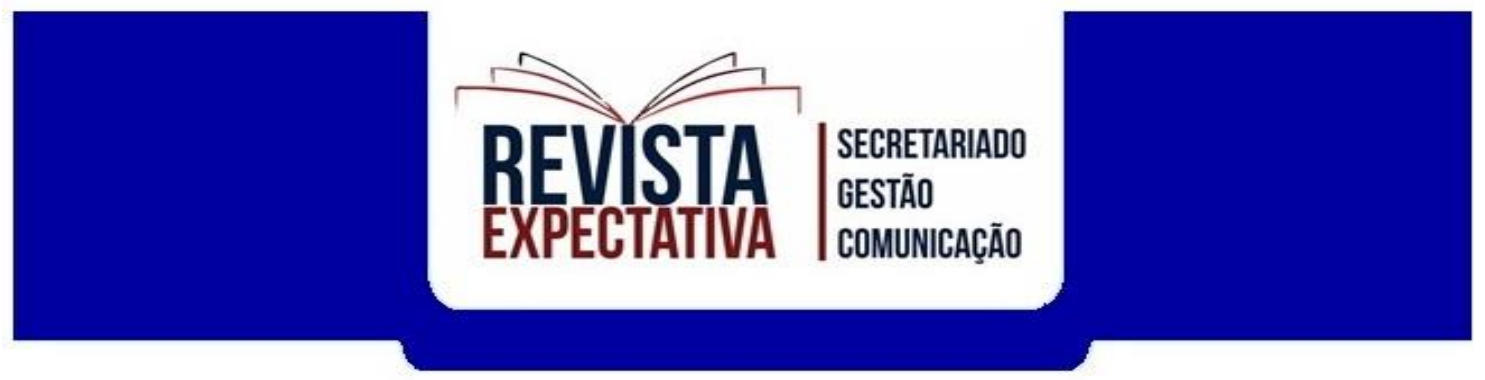

\title{
RELEITURA DA HISTÓRIA SECRETARIAL BRASILEIRA SOB A ÓTICA DO COMPROMISSO, DO PERTENCIMENTO E DA IDENTIDADE
}

Katia Denise Moreira ${ }^{1}$, Stefani de Souza², Juliana Cidrack Freire do Vale ${ }^{3}$, Luci Mari Aparecida Rodrigues ${ }^{4}$

Resumo: A partir da premissa de que a identidade da profissão secretarial é resultado de um processo de transformação histórica, que evoluiu da alienação para o comprometimento e, deste para o pertencimento, este estudo busca refletir acerca do processo de evolução da profissão secretarial, sob a ótica dos fenômenos do pertencimento e da identidade. Em termos metodológicos, tratase de um estudo bibliográfico e documental de abordagem qualitativa. Após a descrição dos elementos constituintes dos fenômenos do pertencimento e da identidade, correlacionou-se os fatos históricos que caracterizam a profissão secretarial com as três unidades analíticas apresentadas. Os dados levantados foram categorizados e analisados com o auxílio da técnica de análise de conteúdo. Como resultado, constatou-se que houve a transformação do sujeito secretário e de seu status quo, fato que o afastou da passividade e da alienação dos primeiros anos de atuação profissional. Assim, infere-se que 0

1 Doutora em Administração pela Universidade Federal de Santa Catarina (UFSC). Mestra Profissional em Administração Universitária pela Universidade Federal de Santa Catarina (UFSC). Especialista em Gestão de Pessoas e Processos pela Faculdade de Ciências Sociais de Florianópolis (CESUSC). Graduada em Letras - Secretariado Executivo em Inglês pela Universidade Federal de Santa Catarina (UFSC). É Assessora do Gabinete da Reitoria da Universidade Federal de Santa Catarina e Secretária Geral da Associação Brasileira de Pesquisa em Secretariado (ABPSEC). Professora Voluntária do Departamento de Administração da Universidade Federal de Santa Catarina (UFSC). https://orcid.org/0000-00031946-8423

2 Mestra Profissional pelo Programa de Pós-Graduação em Administração Universitária da Universidade Federal de Santa Catarina (UFSC). Especialista em Secretariado com ênfase em Gestão de Pessoas e Processos no Complexo de Ensino Superior de Santa Catarina (CESUSC). Bacharel em Secretariado Executivo pela UFSC. Servidora Pública Federal no cargo de Secretária Executiva da Direção do Centro Tecnológico da UFSC. https://orcid.org/0000-0002-2336-0899

${ }^{3}$ Mestre em Administração e Controladoria (PPGA) pela Universidade Federal do Ceará (UFC). Especialista em Administração de Recursos Humanos e Graduada em Secretariado Executivo, ambos pela mesma Universidade. Atualmente exerce o cargo de Secretária Executiva na Universidade Federal de Santa Catarina (UFSC). https://orcid.org/0000-0002-4680-195X

${ }^{4}$ Doutoranda em Administração pela Universidade Federal de Santa Catarina (UFSC), na linha de pesquisa de Gestão Universitária. Mestre em Administração e Especialista em Sistemas de Planejamento e Gestão, ambos pela UFSC. Bacharel em Secretariado Executivo pela Universidade Estadual do Centro-Oeste (UNICENTRO). Secretária Executiva no Centro Socioeconômico da UFSC. https://orcid.org/0000-0002-7307-2078

Editor: Cezar Roberto Versa

Recebido em: 29/10/2019 - Revisado em: 08/02/2020 - Aprovado em: 08/04/2020

Revista Expectativa- e-ISSN 1982-3029 - v.19 - n.1 - jan./jun. - 2020 
comprometimento, associado ao pertencimento, são elementos presentes da história do secretariado, cujos resultados nos dias atuais materializam-se na identidade secretarial.

Palavras-chave: Secretariado. Pertencimento. Comprometimento. Identidade. Abstract: Based on the premise that the executive assistant identity is the result of a process of historical transformation that has evolved from alienation to commitment and, from the last to belonging, this study aims to reflect on the process of evolution of the secretarial profession, under the perspective of the phenomena of belonging and identity. In methodological terms, this is a bibliographic and documentary study with a qualitative approach. After describing the constituent elements of the phenomena of belonging and identity, the historical facts that characterize the secretarial profession were correlated with the three analytical units presented. The collected data were categorized and analyzed with the aid of the content analysis technique. As a result, it was verified that there was a transformation of the executive assistant and his status quo, which removed him from the passivity and alienation of the first years of professional activity. Thus, we can infer that the commitment, associated with belonging, are present elements of the history of the executive secretariat, whose results nowadays materialize in the secretarial identity.

Keywords: Executive Secretariat. Belonging. Commitment. Identity.

\section{INTRODUÇÃO}

Nos últimos anos a identidade passou a fazer parte do vocabulário acadêmico, empresarial e social de forma expressiva, compreendida como algo que não pode ser inventado ou descoberto, mas sim, moldado de acordo com as vivências dos indivíduos. Sobre tal entendimento, Dieterich e Ferro (2012) dizem que a identidade é entendida como algo flexível e adaptável, visto que é passível de testes e experimentações, conforme o contexto social em que 0 indivíduo se encontra inserido.

Acerca da flexibilidade e adaptabilidade inerentes à identidade, Bauman (2005) teorizou sobre a não solidez do pertencimento e da identidade, o que os caracteriza como elementos negociáveis e revogáveis. No entanto, o autor chama a atenção sobre a possibilidade do alicerçamento de tais fenômenos, quando compreendidos pelo sujeito como fatores de transformação de uma realidade, que pode ser a do próprio indivíduo ou do ambiente em que ele se 
instala.

Todavia, para que tal dinamicidade aconteça, vale relembrar o posto por Barbier (1996), quanto argumentou que é preciso o estabelecimento de um compromisso, por parte do sujeito, encadeado com um processo de formação e de autointerrogação sobre as transformações identitárias, ocorridas por meio de experiências sociais, acadêmicas e profissionais. O posto por Barbier (1996) alinha-se ao teorizado por Freire (2011), quando este expõe que o indivíduo só se compromete quando é capaz de agir, refletir e produzir ações que sustentem uma transformação autêntica.

Ainda sobre a identidade, tem-se que o sujeito, antes de ser um profissional, possui uma personalidade, no entanto, seu comprometimento profissional perpassa o da individualidade $\mathrm{e}$, assim, há a necessidade de conciliação de ambos aspectos (FREIRE, 2011). Nessa direção, a identidade é tida como um componente direcional do compromisso, que incorpora as emoções da pessoa, sendo empregada para o comprometimento com a carreira e o comprometimento profissional (ROWE; BASTOS, 2008).

Diante do exposto e considerado o foco da pesquisa, no que se refere à importância dos campos profissional e formativo para o estudo da identidade da área secretarial e, a partir da premissa de que a identidade da profissão de secretário é resultado de um processo de transformação histórica, que evoluiu da alienação para o comprometimento e, deste para o pertencimento, este estudo busca a resposta para a problemática: como ocorreu o processo de evolução histórica da profissão secretarial, sob a ótica dos fenômenos do compromisso, do pertencimento e da identidade?

A fim de responder tal indagação, tem-se como objetivo deste estudo refletir acerca de como ocorreu o processo de evolução histórica da profissão secretarial, sob a ótica dos fenômenos do compromisso, do pertencimento e da identidade. Para tanto, verificou-se, em Décadas, o posicionamento e a postura assumida pelo secretário no ambiente organizacional, assim como aspectos históricos da profissão no Brasil; discutiram-se questões sobre o comprometimento e a falta dele (retratada pela alienação) e também, tratou-se da associação entre comprometimento - pertencimento - identidade. A pesquisa se justifica pela oportunidade de rever a história secretarial sob uma 
ótica diferenciada, por meio de uma discussão que tem como pontos de partida elementos que compõem um conjunto de significados, os quais emergem da realidade de uma profissão, que se supõe, construiu sua identidade ancorada em ações e convicções que foram fortalecidas durante os anos, as quais promoveram transformações tanto pessoais, como no status quo ao qual o secretariado se insere.

Em termos estruturais tem-se, primeiramente esta introdução, que contextualiza o tema abordado e apresenta o problema de pesquisa, bem como, o objetivo central e as razões que levaram as autoras a investigar o tema proposto. Na sequência, apresenta-se a fundamentação teórica, na qual são tratados dos aportes estruturantes acerca do tema-problema deste estudo e que, também, serviram como sustentação para a análise de dados. Nesse sentido, foram associados os temas identidade, comprometimento e pertencimento, bem como, foi realizado um breve relato sobre a história do secretariado no contexto brasileiro, com vistas ao alcance dos objetivos. $\mathrm{Na}$ terceira seção, indica-se a metodologia utilizada para a realização deste estudo, a qual seguiu a abordagem qualitativa e as estratégias bibliográfica e documental, cujos dados foram tratados por análise de conteúdo e documental; na quarta são analisados e discutidos os dados e apresentados os resultados da pesquisa. Na quinta e última seção são expostas as considerações finais, seguidas pelas referências utilizadas no decorrer da pesquisa.

\section{REFERENCIAL TEÓRICO}

\subsection{A ASSOCIAÇÃO ENTRE COMPROMISSO, PERTENCIMENTO E IDENTIDADE}

O homem é um ser histórico, fruto do meio, no entanto, este será resultado da ação desse sujeito, que pode, de forma consciente, transformá-lo e, a partir do momento que transforma o meio, o faz também consigo (FREIRE, 2011). Freire (2011) reforça o exposto ao dizer que o homem é um ser capaz de agir e refletir, a partir da relação homem-realidade e, inserido nesse contexto, produz ações que transformam essa realidade. Dessa maneira, a ação e a reflexão 
são inseparáveis da prática e se alinham aos seus âmbitos de inserção.

Ainda sobre a realidade, Freire (2011) sustenta o caráter dinâmico de tal dimensão, já que seria ingenuidade pensar nela como algo dado, estático e imutável. Trata-se, portanto, segundo esse autor, de uma totalidade, cujas partes se encontram em constante interação e, desse modo, as ações devem incidir, não sobre as partes isoladas, mas sim sobre a totalidade, a fim de que a realidade seja verdadeiramente transformada.

Julga-se que a questão da totalidade se alinha à questão dos indivíduos como seres plurais, que para Arendt (2007) significa dizer que apesar de todo homem pertencer à mesma raça, a humana, ninguém é exatamente igual, nunca foi e nunca será. Todavia, apesar das diferenças, o ser humano, por sua própria existência e capacidade de agir e refletir, é um ser capaz de se comprometer (FREIRE, 2011).

Entretanto, é interessante mencionar que o compromisso não é um ato passivo. Ou seja, para se comprometer o indivíduo precisa conhecer a realidade na qual irá se integrar, caso contrário, não poderá agir e refletir sobre as suas ações, não havendo assim, o compromisso autêntico (FREIRE, 2011). Para o autor, "o compromisso seria uma palavra oca, uma abstração, se não envolvesse a decisão lúcida e profunda de quem o assume" (FREIRE, 2011, p. 7). Nessa perspectiva, crê-se ser necessário considerar a dinâmica de interação entre o sujeito, a realidade e o compromisso.

O compromisso pertence a alguém, com uma ou mais identidades em relação a uma realidade. O homem, por exemplo, antes de ser profissional, é ser humano, porém, sua identidade e comprometimento como profissional perpassam sua individualidade e compromisso como homem em si e, assim, ambas as identidades - homem e profissional - devem ser conciliadas (FREIRE, 2011).

Sobre a questão da identidade, vale lembrar que Bauman (2005) diz ser ela originária da "crise do pertencimento", quando da acelerada "liquefação" das estruturas e instituições sociais, que na modernidade, movem-se da fase "sólida" em direção à "fluida". O autor lembra que o pertencimento e a identidade não têm solidez, fato que os torna elementos negociáveis e revogáveis, mas que, no entanto, os caminhos trilhados pelo sujeito e a postura 
que ele assume, principalmente, em termos de determinação frente à "fluidez", são fatores que sustentam o seu pertencimento e a sua identidade.

Ou seja, é na tarefa realizada várias vezes, na persistência para se alcançar alguma coisa, que o pertencimento não se configura como algo alternativo e, assim, consequentemente, a identidade se ancora como verossímil. Para Wollz e Ferreira (2013), a construção da identidade, ocorrida em qualquer âmbito, está associada tanto a ações individuais, como sociais, alicerçadas por referencias locais e globais. Tal relacionamento, segundo os autores é uma via de mão dupla, visto que ao mesmo tempo em que o sujeito se utiliza do contexto em que está inserido, para a criação de sua identidade, é a partir dela que ele contribui para com as transformações dessa realidade.

A esse contexto se insere a ideia do comprometimento profissional, que Freire (2011) caracteriza como sendo uma dívida do homem para com a sociedade em que está inserido. Nesse sentido, compreende o autor que é necessário associar o compromisso genérico/de cidadão com o de profissional e, atenta para o fato de que o último perpassa o primeiro e vai além, porém, não pode se distanciar dele. Freire (2011) finaliza seu pensamento indicando o aperfeiçoamento constante, como um dos elementos que fortalecem 0 compromisso profissional: "Quanto mais me capacito como profissional, quanto mais sistematizo minhas experiências, quanto mais me utilizo do patrimônio cultural, que é patrimônio de todos e ao qual todos devem servir, mais aumenta minha responsabilidade com os homens" (FREIRE, 2011, p. 10).

A linha teórica de Freire (2011) está relacionada à questão de aperfeiçoamento e desenvolvimento de Bauman (2005), que trata da ampliação do conhecimento do indivíduo a partir do questionamento, da crítica, da busca por mudanças. Tais ações vão ao encontro do exposto por Arendt (2007), quando diz que para que o homem não se torne um ser social artificial, é preciso que ele reflita sobre a realidade, que por sua vez é carregada de variações, com vistas ao questionamento e à transformação de si próprio e do status quo. A autora complementa seu apontamento, com a consideração de que a atuação do sujeito, nos termos indicados, o afasta da neutralidade e da alienação e o aproxima do comprometido, fato que, acredita-se, consequentemente, consolidar o pertencimento e a identidade. 
Sobre a alienação, vale destacar que Paul Lafarge, em 1883, instalado em uma sociedade excessivamente proletária, criticou o trabalho mecanicista ao constatar que os operários, embrutecidos pelo seu vício (o trabalho) não conseguiam refletir sobre ele (LAFARGE, 2000). Na mesma direção, Freire (2011) apresenta a concepção de o homem não ser um simples objeto da técnica, mas sim, o detentor dela. O autor explica, sobre seu posicionamento, que caso o profissional venha a se tornar um escravo das técnicas, Ihe faltará a criatividade e relacionada a ela, surge a inautenticidade, a insegurança e a frustração. A tendência, segundo Freire (2011), é se submeter à forma, sem compreender o conteúdo que a alicerça, uma vez que, a alienação, por sua superficialidade, estimula o formalismo, a subordinação e a obediência. $E$, desse modo, o pertencimento e a identidade tornam-se processos frágeis.

Em síntese é possível compreender, a partir do ora discutido, que só é capaz de se sentir pertencente aquele que se insere em um contexto, a ponto de transformar o ambiente e a ele próprio, com base no agir e no refletir sobre os seus atos. Sob essa perspectiva, Bauman (2005) e Freire (2011) dizem que, para mudar uma sociedade, com profissionalismo e transformá-la de acordo com propostas fundamentadas, é necessário estar comprometido e se identificar com a causa que se defende. Destaca-se ainda, que o aperfeiçoamento/desenvolvimento constante (FREIRE, 2011) deve fazer parte do compromisso de um profissional, seja ele qual for, a fim de que sua visão acerca da realidade, sustentada pela ação-reflexão, possa ser cada vez mais crítica. Tal ato resulta no compromisso autêntico, fato que, segundo Arendt (2007), faz com que o sujeito atue, no sentido de transformar sua realidade e obtenha como resultante uma obra concreta.

\subsection{A HISTORICIDADE DO SECRETARIADO NO CONTEXTO BRASILEIRO}

A historicidade da profissão secretarial é tema amplamente discutido em estudos da área. As origens do secretariado, assim como, a jornada evolutiva do sujeito, hoje, secretário, está associada à história da humanidade e é matéria discutida por autores como Natalense (1998), Castelo (2007), Portela e Schumacher (2006), Nonato Júnior (2009), entre outros. Nessa direção, 
ressalta-se que o secretariado, com o transcorrer do tempo, enfrentou situações fatigantes e conflituosas, que tiveram como consequência o alcance de uma postura mais independente para atuação no mercado de trabalho (DURANTE, 2009).

Sobre 0 mercado de trabalho, destaca-se 0 caráter exigente contemporâneo, que demanda por profissionais diferenciados. No que se refere ao secretariado à questão de ser um ator multitarefas exige do profissional um conjunto de competências, dentre as quais se citam a capacidade de realização, a criatividade e a inovação, a gestão de pessoas, o compromisso com os resultados, a orientação para o cliente, o pensamento estratégico, 0 trabalho em equipe, a gestão de mudanças, a gestão de projetos e a liderança (NEIVA; D’ELIA, 2009). Vale dizer que, o desenvolvimento de competências encontra na formação secretarial um de seus principais alicerces (ALMEIDA; ROGEL; SHIMOURA, 2010).

Considerada a conjunção, formação secretarial e demandas do mercado atual, crê-se que o contexto brasileiro é protagonista naquilo que diz respeito ao pertencimento e à busca pela identidade do secretariado, visto que é fato reconhecido que em outros países a consolidação da profissão é ainda um desafio. Nesse sentido, o Quadro 1 caracteriza, em décadas, o posicionamento e a postura assumida pelo secretário no ambiente organizacional, assim como, ilustra momentos históricos da profissão no Brasil, a fim de sustentar aquilo que ora se discute.

Quadro 1 - Evolução da profissão secretarial no Brasil

\begin{tabular}{|l|l|}
\hline Periodização & Características da profissão \\
\hline Anos 1950 & - Início da atuação secretarial na estrutura empresarial brasileira. \\
& $\begin{array}{l}\text { - Secretário executor de tarefas - aplicação de técnicas secretariais como: } \\
\text { taquigrafia, datilografia, arquivo, atendimento telefônico e anotações de } \\
\text { recados. }\end{array}$ \\
\hline
\end{tabular}




\begin{tabular}{|c|c|}
\hline Anos 1960 & $\begin{array}{l}\text { - Início dos treinamentos gerenciais - profissional de secretariado permanece } \\
\text { executor de tarefas. } \\
\text { - Ter um secretário passa a ser um status - na mentalidade do empresário } \\
\text { brasileiro tal ato é compreendido como "valorização". } \\
\text { - Início das Associações dos profissionais de secretariado: Associação das } \\
\text { Secretárias do Brasil (ASB), em São Paulo em 1964; Movimento "Clube das } \\
\text { Secretarias", no Rio de Janeiro em } 1965 \text { e Associação das Secretárias, em } \\
\text { Porto Alegre em } 1968 . \\
\text { - 1o Curso de Graduação em Secretariado no Brasil (1969) - Universidade } \\
\text { Federal da Bahia. }\end{array}$ \\
\hline Anos 1970 & $\begin{array}{l}\text { - O secretário passa a ser percebido como membro ativo na gerência - } \\
\text { atuação mais dinâmica e abrangente - ganha o respeito nas organizações. } \\
\text { - Associações de Classe começam a atuar no Brasil, no sentido de reunir e } \\
\text { agrupar a classe, com o propósito de conscientização e aprimoramento } \\
\text { profissional e ainda, buscar uma nova imagem da profissão. } \\
\text { - Criação do Clube das Secretárias de Pernambuco em } 1971 \text { e da Associação } \\
\text { das Secretárias do Espírito Santo em } 1973 \text {. } \\
\text { - I Convenção Nacional de Secretárias, no ano de 1973. } \\
\text { - II Convenção Nacional de Secretárias, no ano de 1974. } \\
\text { - Criação da Associação Brasileira de Entidades de Secretárias (ABES) em } \\
\text { 1975. } \\
\text { - Lei n. 1.421/77, de } 20 \text { de setembro de 1977, que instituiu o dia } 30 \text { de } \\
\text { setembro como o "Dia Nacional da Secretária". } \\
\text { - Lei n. } 6.556, \text { de } 5 \text { de setembro de } 1978 \text { - primeira Lei de regulamentação da } \\
\text { profissão secretarial. } \\
\text { - Reconhecimento, pelo Ministério da Educação, do Curso de Graduação em } \\
\text { Secretariado da Universidade Federal de Pernambuco (1978). }\end{array}$ \\
\hline
\end{tabular}




\begin{tabular}{|c|c|}
\hline Anos 1980 & $\begin{array}{l}\text { - A profissionalização demanda do secretário o exercício da profissão com } \\
\text { mais responsabilidade, busca por aprimoramento constantemente, } \\
\text { conscientização profissional, formação técnica e aperfeiçoamento cultural. } \\
\text { - O despertar da era da qualidade e da informática - promove a ação conjunta } \\
\text { entre chefes e secretários (administração participativa). } \\
\text { - O trabalho passa a ser em equipe. } \\
\text { - Sancionada a Lei } n .07 .377 \text {, de } 30 \text { de setembro de } 1985 \text {, que regulamenta a } \\
\text { profissão de secretário. O marco legal estabelece critérios para o exercício da } \\
\text { profissão de Técnicos em Secretariado e Secretariado Executivo. }\end{array}$ \\
\hline & - Publicação do Código de Ética do Profissional de Secretariado em 1989. \\
\hline Anos 1990 & $\begin{array}{l}\text { - As megatendências (globalização) exigem profissionais de secretariado } \\
\text { diferenciados. } \\
\text { - A era da competência demanda por profissionais polivalentes e atualizados, } \\
\text { com capacidade produtiva, em busca de resultados. } \\
\text { - Não só se recebe ordens, mas também se orienta e dá opiniões. } \\
\text { - O secretário deixa de ser "propriedade particular" do gerente a quem } \\
\text { assessora e passa a ser um membro da organização. } \\
\text { - Desaparece a moça elegante, bem-vestida e apenas digitadora. } \\
\text { - Nasce um outro perfil: gestor, empreendedor e consultor. } \\
\text { - Criação da Federação Nacional de Secretárias e Secretários (FENASSEC). } \\
\text { - Aprovação da Lei n. } 0 \text { 9.261, de } 30 \text { de janeiro de } 1996 \text {, que altera a redação } \\
\text { dos incisos I e II do art. } 2^{\circ} \text {, o caput do art. } 3^{\circ} \text {, o inciso VI do art. } 4^{\circ} \text { e o } \\
\text { parágrafo único do art. } 6^{\circ} \text { da Lei n. } 7.377 \text {, de } 30 \text { de setembro de } 1985 \text {. }\end{array}$ \\
\hline
\end{tabular}




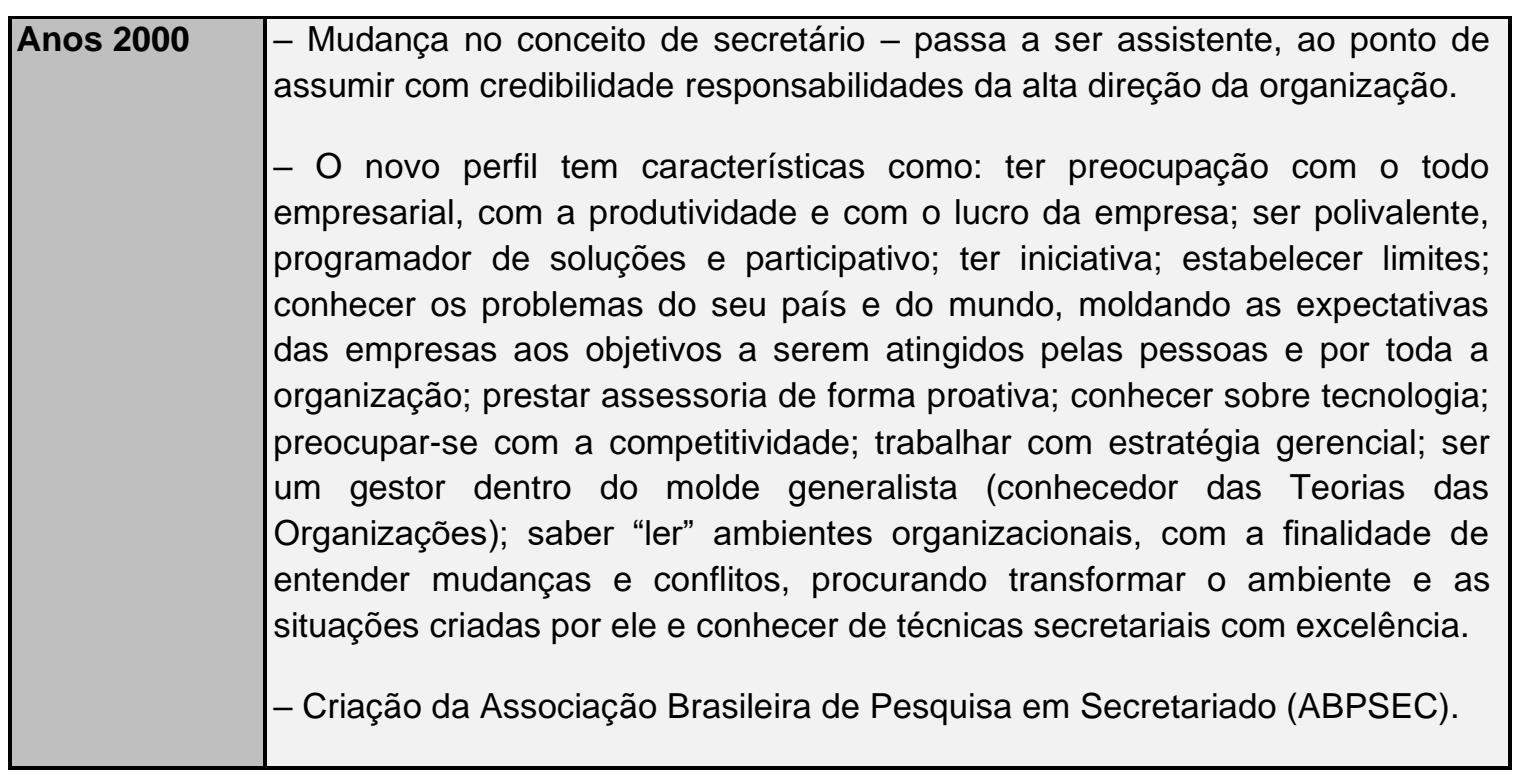

Fonte: Elaborado pelas autoras com base em Portela e Schumacher (2006) e Sabino (2017)

Constata-se, por meio do Quadro 1, que a historicidade da profissão secretarial no contexto brasileiro sofreu variações significativas. Observa-se, por exemplo, que o início da industrialização no país, na Década de 1950, ampliou a inserção do profissional no mercado, no entanto, aqueles foram momentos em que o secretário apenas executava tarefas. Com o transcorrer dos anos foram adicionadas conquistas expressivas ao histórico do secretariado, de formação e de posicionamento em relação ao ambiente organizacional; marcos que possibilitaram a transição de uma atuação passiva para àquela ativa, inclusive, promovendo a mudança do conceito daquilo que se entendia por secretário, conforme indicam as características da profissão no ano 2000.

Vale destacar que apesar de evidencias mais significativas da atuação secretarial a partir dos anos 1950 e, da criação de um curso de formação superior na área apenas nos anos de 1960, antes, com a expansão do Ensino Comercial brasileiro, ocorrido, principalmente, a partir das reformas educacionais da Era Vargas (1931-1943) o secretariado já era considerado no campo educacional, por meio do diploma de Técnico em Secretariado (SABINO, 2017). A autora constatou, ainda, que o secretariado se insere na educação brasileira com o Curso Especial Feminino - Secretária, da Escola de Comércio Álvares Penteado no ano de 1932. 
Hoje, o secretário assume papéis significativos nas organizações e atividades essencialmente técnicas do passado foram substituídas pela atuação estratégica, como, por exemplo, em casos de gestão de pessoas, de informação, de processos (MOREIRA; OLIVO, 2012; RODRIGUES; LAVARDA; MARTINS, 2017). O secretário executivo contemporâneo tem domínio de suas competências e, pode além de alcançar níveis elevados de autonomia nas organizações, expandir seu campo de atuação, como em casos de empreendedorismo (LEAL; DALMAU, 2014). Assim, discutida a teoria que sustenta este estudo, na sequência, trata-se dos procedimentos metodológicos que ancoram a reflexão ora proposta.

\section{PROCEDIMENTOS METODOLÓGICOS}

A abordagem adotada para esta pesquisa é a qualitativa, no intuito de caracterizar o processo de evolução da profissão secretarial, alinhado aos fenômenos do compromisso, do pertencimento e da identidade. Esse tipo de investigação pretende compreender significados que indivíduos ou grupos conferem às situações que se apresentam, diante de uma conjuntura social (CRESWELL, 2009). Nesse sentido, não se busca a quantificação, a partir de mensuração de resultados e em detrimento ao processo de construção de uma dada realidade (TRIVIÑOS, 2012), pretende-se, ao contrário, discutir acerca de elementos que compõem um conjunto de significados, os quais emergem do contexto em que os fatos se encontram, ou seja, na história do Secretariado, por meio da compreensão de sua representatividade na sociedade e em direção à própria construção de uma identidade profissional aliada, também, à busca pela cientificidade no Campo Secretarial.

Diante do exposto e em consonância a abordagem mencionada, a qual, de acordo com Babbie (2010), contempla diversos estudos que visam, principalmente, a descrição de situações e eventos, os objetivos delineados nesta pesquisa são descritivos. Como estratégia de estudo, utilizou-se de pesquisa documental e bibliográfica. A primeira é caracterizada por se basear em registros e documentos como fontes principais de dados e, tanto se refere a materiais recentes, como históricos (SAUNDERS; LEWIS; THORNHILL, 2009). 
A segunda é conceituada um conjunto de conhecimentos sistematizados, provenientes de bases compostas por materiais publicados, tais como livros, artigos de revistas acadêmicas, de periódicos científicos, dentre outros (VERGARA, 2007). Assim, o uso dessa estratégia serviu de alicerce para os construtos teóricos determinantes deste estudo, cuja finalidade foi buscar temas relevantes para dar sustentação aos objetivos traçados.

No que concerne aos procedimentos para o tratamento de dados, foram selecionadas as técnicas de Análise de Conteúdo e Documental. Esta última se fundamenta no tratamento de dados secundários, cujas evidências são colhidas em fontes criadas com o propósito de gestão e organização de informações, em âmbito público e privado (SAUNDERS; LEWIS; THORNHILL, 2009). Vale ressaltar que, as evidências documentais analisadas são de bases legais (leis, decretos etc), relacionadas à profissão secretarial.

De acordo com Bardin (2011), a Análise de Conteúdo contempla diversas propostas de métodos complementares para sua realização, dentre os quais se optou pela categorização, que trata de classificar um conjunto constitutivo, formado por elementos selecionados a partir de critérios prédefinidos, os quais possuem características comuns (BARDIN, 2011).

Diante do exposto, categorias delineadas apresentam-se pertinentes quando se encontram alicerçadas em um determinado quadro teórico e estão adaptadas ao material selecionado para ser objeto de análise e, assim, expressarem as intenções do estudo (BARDIN, 2011). Nesse sentido, faz-se a descrição dos elementos constituintes dos fenômenos do compromisso, do pertencimento e da identidade, assim como, dos fatos históricos que caracterizam a profissão secretarial, de modo a correlacionar essas unidades analíticas com base em seus elementos constituintes e presentes no arcabouço teórico a que pertencem. Em continuidade, passa-se à apresentação dos resultados e discussões acerca da pesquisa.

\section{RESULTADOS E DISCUSSÕES}

Conforme exposto no arcabouço teórico deste estudo, a identidade se manifesta a partir do sentimento de pertencimento do indivíduo em relação a 
uma determinada realidade (BAUMAN, 2005; FREIRE, 2011). Na direção contrária está a alienação, que desde o século XIX recebe críticas pela sua característica de fomentar o trabalho mecanicista, fato que não permite ao sujeito refletir sobre como o trabalho é realizado ou ainda, como poderia ser melhorado (LAFARGE, 2000).

Dessa maneira, acredita-se que a alienação interfere diretamente na identidade, uma vez que, se o indivíduo não se amalgama ao meio, com vistas a compreendê-lo ou mesmo, modificá-lo, não há comprometimento, apenas se "produz" por necessidade, talvez fisiológica, talvez de segurança ou ambas. Nesse contexto, não existe o pertencimento, elemento, que segundo a teoria, é um condicionante da identidade e só se manifesta quando o sujeito, a partir de um processo interpretativo, assimila que a realidade em que está situado é condizente com sua vontade de colaborar para com a evolução, tanto da circunstância em si, quanto sua própria.

Ao ponderado associa-se a historicidade do secretariado no contexto brasileiro, país que em comparação a outros, a profissão ascendeu positivamente desde as primeiras evidências da atuação nas Décadas de 1930, 1940 e, mais efetivamente, em 1950. Ao se refletir sobre a trajetória secretarial nessa conjuntura específica, evidenciam-se transformações tanto da profissão, quanto do sujeito secretário, que amparado por uma série de movimentos que buscaram o aperfeiçoamento e o reconhecimento da classe, conquistaram posicionamento de relevância e o desenvolvimento de um perfil diferenciado, em termos de atuação no âmbito organizacional. Assim, busca-se a partir do ilustrado na Figura 1, refletir sobre a historicidade secretarial alinhada às concepções de comprometimento, alienação, pertencimento e identidade.

Figura 1 - Associação da historicidade secretarial com o comprometimento, a alienação, o pertencimento e a identidade. 


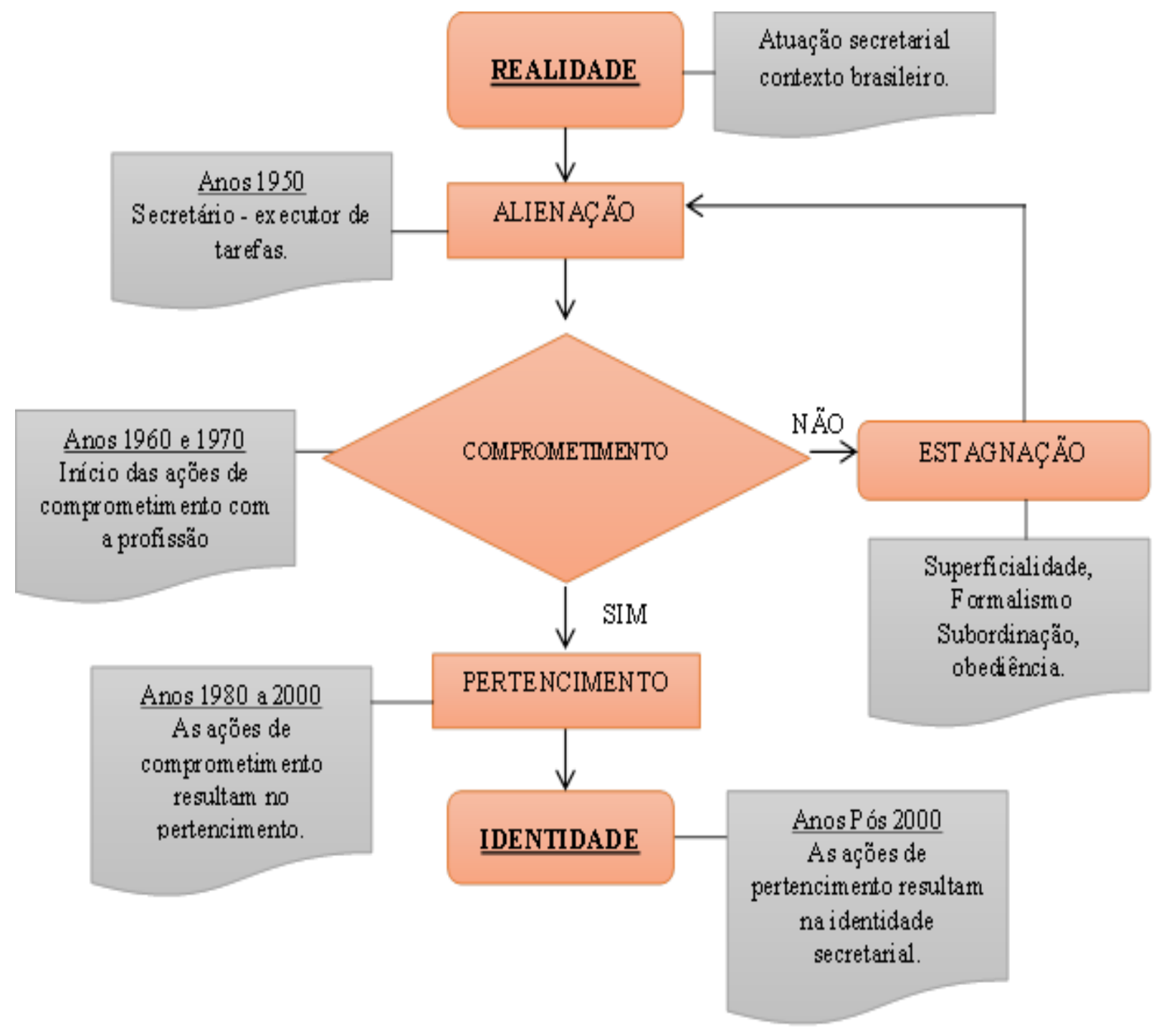

Fonte: Elaborado pelas autoras (2017)

A Figura 1 permite a compreensão da associação proposta por meio de um processo, que tem como realidade a conjuntura histórica da atuação secretarial no Brasil. Conforme ilustrado no Quadro 1, as atividades de secretariado iniciam no país, mais significativamente, na Década de 1950. Naquele momento se vivia a era da industrialização e, muitas empresas, inclusive multinacionais, começam a se instalar no território brasileiro.

Considerado o ambiente organizacional, local principal da ação secretarial e a nova configuração do mercado, as oportunidades de trabalho para o secretário se confirmam. Todavia, naqueles tempos o profissional era apenas um executor de tarefas, cuja atividade primeira era a aplicação de 
técnicas secretariais (taquigrafia, datilografia, arquivo, atendimento telefônico e anotações de recados) (PORTELA; SCHUMACHER, 2006). Julga-se que se tratava de uma época em que o secretário era escravo das técnicas, em que a passividade ancorava a submissão, que por consequência, estimulava a superficialidade, o formalismo, a subordinação e a obediência cega (FREIRE, 2011), comprometendo, assim, o envolvimento do sujeito com a sua realidade e, nesse sentido, a condição de aferir pertencimento e identidade.

Décadas depois, nos anos de 1960 e 1970, verificam-se movimentos contrários à posição estandardizada do profissional de secretariado. Apesar de a natureza executora ainda permanecer, movimentos como a criação das associações dos profissionais de secretariado, a criação do primeiro curso de Graduação em Secretariado (1960) e o reconhecimento, pelo Ministério da Educação, do Curso de Graduação em Secretariado da Universidade Federal de Pernambuco (1978), entre outras, se configuram como os primeiros atos do comprometimento dos sujeitos com a profissão. Acredita-se que tal postura, alinha-se ao posto por Bauman (2005) e Freire (2011) quando tratam da busca do aperfeiçoamento e do desenvolvimento como uma forma de fortalecer 0 compromisso com aquilo que se deseja modificar, seja o ambiente, seja o pessoal.

Verificam-se na história brasileira do secretariado, ainda, fundamentos que permitem afirmar que com o transcorrer do tempo o comprometimento se condensa, principalmente nos anos de 1980 a 2000, quando importantes marcos legais são sancionados, como, por exemplo, a Lei n.ำ 7.377, que regulamenta a profissão secretarial e a publicação do Código de Ética do profissional de Secretariado. A criação da Federação Nacional de Secretárias e Secretários (FENASSEC) e da Associação Brasileira de Pesquisa em Secretariado (ABPSEC) reforçam os atos de busca de um alicerce, seja mercadológico, seja científico. Ressalta-se também, que a profissionalização, elemento de destaque, disposto nos instrumentos legais, alinhada às mudanças globais vivenciadas pelas organizações, como a era tecnológica e das competências, exigiram do secretário responsabilidade e busca por aprimoramento constante.

Os atos protagonizados pelos sujeitos secretários vão ao encontro do 
posto por Arendt (2007), ou seja, houve reflexão sobre uma realidade, que foi questionada e, como resultado, alcançou-se a transformação do próprio sujeito e de seu status quo, fato que o afastou (profissional de secretariado) da passividade e da alienação dos primeiros anos de atuação secretarial. Vale lembrar que o pertencimento não tem solidez (BAUMAN, 2005) e que somente se sustenta frente à determinação do indivíduo, que compreende e realiza, com persistência, tarefas que levam à evolução.

Considerado o ora discutido, acredita-se que o comprometimento, associado ao pertencimento, são elementos presentes da história secretarial, cujos resultados nos dias atuais materializam-se na identidade secretarial. Tal afirmativa se sustenta nos fatos de o profissional de secretariado ter buscado, a partir da reflexão, aperfeiçoamento e desenvolvimento, bem como a transformação de uma realidade passiva para outra proativa, na qual a execução de atividades ainda é presente, porém vem acompanhada da possibilidade da atuação consultiva, empreendedora, gerencial e estratégica (MOREIRA; OLIVO, 2012; PORTELA; SCHUMACHER, 2006; RODRIGUES; LAVARDA; MARTINS, 2017).

Julga-se, por fim, que a história secretarial no Brasil é caracterizada pelo compromisso autêntico, conforme posto por Arendt (2007), uma vez que o sujeito secretário protagonizou fatos que resultaram em uma obra concreta, a "identidade secretarial brasileira”. Diante de tais evidências, crê-se que o futuro da profissão será marcado por outras ações, que complementarão aquilo que já se conquistou, desde que, a "fluidez" da modernidade não interfira na identidade conquistada até o momento presente.

\section{CONSIDERAÇÕES FINAIS}

A historicidade da profissão secretarial, no contexto brasileiro, é marcada por momentos de conquistas, conforme destacado no decorrer desta reflexão. Não obstante, é preciso ressaltar que os eventos que proporcionaram a evolução da carreira foram se construindo ao longo do tempo e partiram de um status quo em que a alienação ou, em outras palavras, a passividade na postura do secretário dominava sua atuação. No entanto, essa situação não 
tem duração delongada, visto que, já na segunda Década de ação efetiva nas organizações brasileiras, os profissionais de secretariado começam a mover-se em direção às questões do comprometimento.

Considerado tal cenário, este estudo teve como propósito refletir acerca de como ocorreu o processo de evolução histórica da profissão secretarial, sob a ótica dos fenômenos do compromisso, do pertencimento e da identidade, elementos que se julga, são produtos de um processo de comprometimento ocorrido durante a evolução histórica do secretariado. Dessa maneira, buscouse apresentar uma releitura da historicidade secretarial sob uma ótica diferenciada, que trouxesse fundamentos de uma linha mais filosófica, mesclada com a funcionalidade predominante no contexto da profissão ora discutida.

Assim, em síntese, ao se associar os fatos da história do secretariado com a questão do comprometimento e vinculado a ele o pertencimento e a identidade, constatou-se que houve transformações tanto do próprio sujeito secretário, quanto do seu status quo de atuação, fato que o afastou da passividade e da alienação dos primeiros anos de atuação profissional. Sobre essa percepção, infere-se que os resultados apresentados nos dias atuais se materializam na formação de uma identidade profissional, em que a reflexão, o aperfeiçoamento e o desenvolvimento foram utilizados como forma de fortalecer o compromisso com aquilo que se desejava modificar.

Acredita-se, ao fim da pesquisa, que os dados responderam positivamente à problemática. Como consequência, alcançou-se o objetivo principal, em que a análise da conjuntura histórica da atuação secretarial no Brasil permitiu a compreensão de processos de percepção de uma realidade de alienação, que foi transposta ao longo do tempo e resultou em um movimento de busca pelo comprometimento, por uma causa. Por conseguinte, gerou-se um sentimento de pertencimento no momento presente o qual, consequentemente, alicerçou a formação de uma identidade profissional contemporânea substanciada.

No que tange às limitações do estudo, adotou-se uma perspectiva de análise teórica quanto à correlação entre os temas estruturados e a busca pela resposta ao objetivo central de investigação. Nesse sentido, acredita-se que 
trabalhos empíricos, relacionados, principalmente, com o comprometimento, trarão versões práticas daquilo que ora se reflete em termos teóricos. Desse modo, para futuros trabalhos, sugere-se a realização de pesquisas com profissionais da área de secretariado, para averiguar como as temáticas abordadas se manifestaram na sua própria formação identitária, bem como investigar questões ligadas ao vínculo profissional e à carreira.

\section{REFERÊNCIAS}

ALMEIDA, W. G.; ROGEL, G. T. S; SILVA A. S. Mudanças de paradigmas na gestão do profissional de secretariado. Revista de Gestão e Secretariado, v. 1, n. 1, p. 46-68, 2010.

ARENDT, H. A Condição Humana. In: ARENDT, H. A Condição Humana. Rio de Janeiro: Forense Universitária, 2007.

BABBIE, E. The Practice of Social Research. 12th. ed. Wadsworth: Cengage Learning, 2010.

BARBIER, J. De l'usage de la notion d'identité en recherche notamment dans le domaine de la formation. Éducation Permanente, v. 3, n. 128, p. 11-25, 1996.

BARDIN, L. Análise de conteúdo. São Paulo: Edições 70, 2011.

BAUMAN, Z. Identidade: entrevista a Benedetto Vecchi. Rio de Janeiro: Jorge Zahar Ed., 2005.

CASTELO, M. J. A formação acadêmica e a atuação profissional do secretário executivo. 2007. Disponível em:

http://www.fenassec.com.br/site/pdf/artigos_trab_cientificos_consec_3lugar.pdf. Acesso em: 18 jan. 2017.

CRESWELL, J. W. Research design: qualitative, quantitative and mixed approaches. 3. ed. London: Sage Publications, 2009.

DIETERICH, B. R.; FERRO, J. Perfil de liderança e identidade do profissional de secretariado. Revista do Secretariado Executivo, Passo Fundo, n. 8, p. 
$52-61,2012$.

DURANTE, D. G.; FÁVERO, A. A. Gestão secretarial: formação e atuação profissional. Santa Maria: UPF Editora, 2009.

FREIRE, P. O Compromisso do Profissional com a Sociedade. In: FREIRE, P. Educação e Mudança. São Paulo: Paz e Terra, 2011.

GODOY, A. S. A pesquisa qualitativa e sua utilização em administração de empresas. Revista de Administração de Empresas, v. 35, n. 4, p. 65-71, 1995.

LAFARGE, P. O Direito a Preguiça. 2. Ed. São Paulo: UNESP, 2000.

LEAL. F. G; DALMAU, M. B. L. Análise das competências secretariais requeridas pela Universidade Federal de Santa Catarina em comparação ao perfil profissiográfico do secretário executivo. Revista de Gestão e Secretariado, v. 05, n. 03, p.143-174, 1 dez. 2014.

MOREIRA, K. D.; OLIVO, L. C. C. de. O Profissional de Secretariado Executivo como Mediador de Conflitos. Revista de Gestão e Secretariado, [s.I.], v. 03, n. 01, p.30-53, 1 jun. 2012.

NATALENSE, M. L. C. A secretária do futuro. Rio de Janeiro: Qualitymark. 1998.

NEIVA, E. G.; D'ELIA, M. E. S. As novas competências do profissional de secretariado. IOB Informações Objetivas Publicações Jurídicas Ltda, 2009.

NONATO JÚNIOR, R. Epistemologia e teoria do conhecimento em secretariado executivo: a fundação das ciências da assessoria. Fortaleza: Expressão Gráfica, 2009.

PORTELA, K. C. A.; SCHUMACHER, A. J. Ferramentas do secretário executivo. Santa Cruz do Rio Pardo: Viena, 2006.

RODRIGUES, L. M. A; LAVARDA, R. A. B. MARTINS, C. B. O profissional de secretariado executivo: seu papel como gestor de informações no processo de formação da estratégia. Revista Capital Científico, v. 15, n. 3, p. 1-16, 2017. 
ROWE, D. E. O.; BASTOS, A. V. B. Comprometimento ou entrincheiramento na carreira? Um estudo entre docentes do ensino superior. In: XXXII ENANPAD Encontro Nacional dos Programas de Pós-graduação em Administração. 2008, Rio de Janeiro. Anais... Rio de Janeiro: 2008.

SABINO, R. F. A configuração da profissão de secretário em Sergipe: educação, atuação e organização da área (1975-2010). 2017. 387 f. Tese (Pós-Graduação em Educação). Universidade Federal de Sergipe, São Cristóvão, SE, 2017.

SAUNDERS, M.; LEWIS, P.; THORNHILL, A. Research methods for business students. 5. ed. New York: Prentice Hall Inc., 2009.

TRIVIÑOS, A. N. S. Introdução à Pesquisa em Ciências Sociais: a pesquisa qualitativa em Educação. São Paulo: Atlas, 2012.

WOLLZ, L. E. B.; FERREIRA, F. R. Juventude no campo: problematizando a construção da identidade no contexto da sociedade de consumo.

Conhecimento \& Diversidade, v. 5, n. 10, p. 63-72, 2013. Disponível em: $<$ https://revistas.unilasalle.edu.br/index.php/conhecimento_diversidade/article/vi ew/1296/0>. Acesso em: 2 jan. 2018.

VERGARA, S. C. Projetos e relatórios de pesquisa em administração. São Paulo: Atlas S.A., 2007. 